
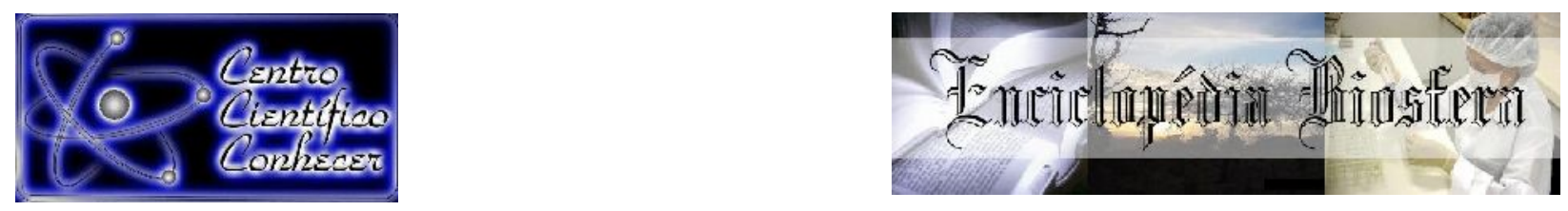

\title{
PERFORMANCE DA CULTURA DO SORGO EM SISTEMAS AGROSSILVIPASTORIS EM CONDIÇÕES SEVERAS DE ESTRESSE HÍDRICO NA REGIÃO SUDOESTE DA AMAZÔNIA
}

\author{
Rodrigo da Silva Ribeiro ${ }^{1}$, Alexandre Martins Abdão dos Passos ${ }^{2}$ \\ ${ }^{1}$ Mestrando em Ciências Ambientais, Universidade Federal de Rondônia - UNIR, Porto \\ Velho, RO, Brasil \\ 2Pesquisador da Embrapa Milho e Sorgo (alexandre.abdao@embrapa.br) Sete Lagoas, MG, \\ Brasil
}

Recebido em: 22/09/2018 - Aprovado em: 23/11/2018 - Publicado em: 03/12/2018

DOI: 10.18677/EnciBio_2018B128

\begin{abstract}
RESUMO
A cultura do sorgo pode representar uma alternativa viável para compor sistemas de produção integrados, especialmente enquanto cultura sucessora da soja em semeaduras tardias no fechamento da safrinha. Objetivou-se avaliar o desempenho agronômico da cultura do sorgo implantada em consórcio com a Braquiária brizantha cultivar Xaraés em sistemas integração lavoura-pecuária-floresta com eucalipto em dois diferentes arranjos espaciais em condição intensa de estresse hídrico. O experimento foi implantado e conduzido na segunda safra em 2017, utilizando o híbrido de sorgo IPA730 1011 consorciado com capim entre renques de eucalipto com 5 anos de idade. Os renques foram compostos por 4 linhas de eucalipto, oriundos de dois clones (GG100 e VM01). As lavouras foram cultivadas em dois espaçamentos entre renques, de 18 e 42 metros. Foram avaliadas o rendimento de grãos, altura de plantas, índice de panícula, massa de mil grãos e massa seca da forragem em diferentes distâncias do componente arbóreo entre os sistemas. Observou-se que as maiores produtividades de grãos ocorreram no espaçamento de 18 metros. Nessa condição a cultura produziu $71,4 \%$ a mais que a média observada no renque de 42 metros. Conclui-se que nas condições de extremo estresse hídrico, o maior adensamento de árvores promove maior rendimento de grãos em sistemas com eucalipto com 5 anos de idade.
\end{abstract}

PALAVRAS-CHAVE: integração lavoura-pecuária-floresta, safrinha, Sorghum bicolor

\section{PERFORMANCE OF SORGHUM CROP IN AGROFORESTRY SYSTEMS UNDER SEVERE WATER STRESS CONDITIONS IN THE SOUTHWEST AMAZON REGION}

\footnotetext{
ABSTRACT

Sorghum crop may represent a viable alternative for set up integrated farming systems, especially at late off-season and in succession to soybeans crops. The aim of this study was to evaluate the agronomic performance of sorghum intercropped with Braquiaria brizantha cv Xaraés in integrated crop-livestock-forest systems. Systems with eucalypt alleys under different spatial arrangements and genotypes 
were used. An experiment was carried out in the 2017, using a grain sorghum hybrid IPA730 1011, intercropped with pasture and eucalyptus. The alleys were set up by 4 rows of eucalyptus trees. The spaces between the alleys were 18 and 42 meters. Plant height, panicle index, one thousand grain mass and grain yield in the sorghum crop and yield of pasture dry biomass were evaluated. The highest grain yields were observed in the 18-meters spatial arrangement. Under this condition, sorghum yielded $71.4 \%$ more than the average observed in the 42 -meter row. It is concluded that under the conditions of extreme water stress, the highest density of trees boosts greater yield in systems with 5-years-old trees.

KEYWORDS: Integrated Crop-Livestock-Forest Systems, off-season crop, Sorghum bicolor

\section{INTRODUÇÃO}

O sorgo (Sorghum bicolor L. Moench) é uma cultura agrícola que vem ganhando destaque no cenário mundial, por apresentar grande importância econômica e social nos contextos e cenários de mudanças climáticas, tendo utilizações desde a alimentação humana e animal até pelas indústrias de alta tecnologia. Fator de importância para sua utilização, é que a planta de sorgo apresenta uma tolerância natural maior para condições de estresse hídrico e solos de baixa fertilidade natural (CANIATO et al., 2014; SANTOS et al., 2018). Razão pela qual a cultura do sorgo tem se configurado como uma opção viável para ser inserida em sistemas de produção no cerrado em condições de safrinha (segunda safra).

A produção mundial da cultura, na safra de 2017/18 deve ser de aproximadamente 58,36 milhões de toneladas, sendo os maiores produtores os Estados Unidos, Nigéria e México, com uma produção de 9,24; 6,5 e 4,5 milhões toneladas, respectivamente (USDA, 2018). O Brasil é o nono maior produtor mundial do grão. Estima-se que a produção supere os 2,1 milhões de toneladas na safra 2017/2018, representando um acréscimo de 12,5\% em relação à safra anterior que foi de 1,86 milhões de toneladas, em uma área de 761,5 mil hectares (CONAB, 2018).

O sorgo apresenta se como uma opção para a região norte do Brasil visando à recuperação de áreas degradadas, especialmente as pastagens. Para tal, uma estratégia reside no consorciamento da cultura do sorgo com plantas forrageiras do gênero braquiária, ou outras, visando o estabelecimento de uma pastagem de alto valor nutritivo na entressafra agrícola (SILVA et al., 2014).

Em diversas regiões da Amazônia, observa-se um período no qual o déficit hídrico promove diminuição na capacidade de suporte das pastagens o que ocasiona uma menor taxa de lotação, tendo como consequência indireta a prática comum de abertura de novas áreas e formação de novas pastagens em áreas de desmatamento de mata nativa visando substituir áreas com baixo potencial de uso (SCHLINDWEIN et al., 2012).

A cultura do sorgo tem sido implantada em épocas de semeadura não recomendadas, que apresentam alto risco climático para o pleno crescimento e desenvolvimento das plantas. Apesar de se apresentar como uma cultura tradicionalmente resiliente ao estresse de seca e solos distróficos, o sorgo ainda é pouco estudado em sistemas consolidados de integração com árvores na região norte do Brasil. Diante do exposto, objetivou-se avaliar o desempenho agronômico da cultura do sorgo implantada em consórcio com a braquiária brizantha Xaraés em 
integração lavoura-pecuária-floresta com eucalipto sob diferentes arranjos espaciais em condições de alto estresse hídrico.

\section{MATERIAL E MÉTODOS}

O experimento foi implantado e conduzido na safra 2017 no Campo Experimental da Embrapa, localizado no município de Porto Velho, Rondônia, $95 \mathrm{~m}$


região, segundo Alvares et al. (2013), é o tropical úmido (Am). A temperatura média anual é de $25,5^{\circ} \mathrm{C}$, com umidade relativa do ar de, aproximadamente, $83 \%$. A precipitação média anual é de $2.000 \mathrm{~mm}$. As precipitações e temperaturas médias diárias observadas durante a safra 2017, englobando a cultura do sorgo, estão representadas abaixo na Figura 1.

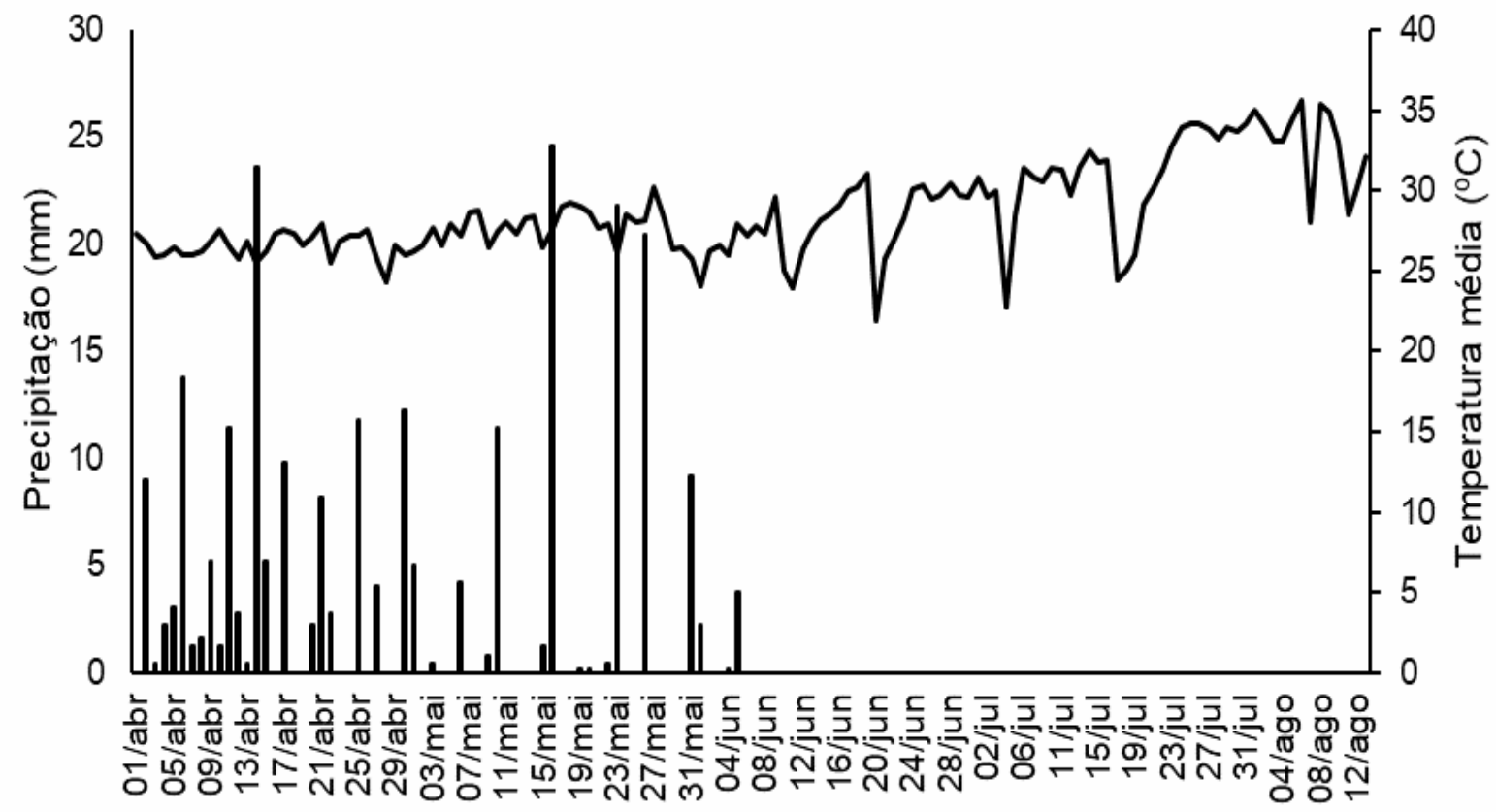

FIGURA 1. Precipitação $(\mathrm{mm})$ e temperaturas médias diárias $\left({ }^{\circ} \mathrm{C}\right)$ no período de abril a agosto de 2017, em Porto Velho, Rondônia. Fonte: Instituto Nacional de Meteorologia 2017.

O solo da área experimental é do tipo Latossolo Vermelho-Amarelo distrófico típico, de textura argilosa (EMBRAPA, 2013). Previamente à instalação do experimento, foram coletadas amostras de solo para determinação dos atributos químicos (Tabela 1).

TABELA 1. Atributos químicos do solo na profundidade de 0 a $20 \mathrm{~cm}$. Matéria orgânica $(\mathrm{MO})$, fósforo $(\mathrm{P})$, potássio $(\mathrm{K})$, cálcio $(\mathrm{Ca})$, magnésio $(\mathrm{Mg})$, acidez potencial $(\mathrm{H}+\mathrm{Al})$, alumínio $(\mathrm{Al})$, capacidade de troca de cátions $\mathrm{pH}_{7}(\mathrm{~T})$ capacidade de troca de cátions efetiva ( $\mathrm{t})$, saturação por alumínio $(\mathrm{m})$ e saturação por bases $(\mathrm{V})$. Porto Velho, Rondônia.

\begin{tabular}{|c|c|c|c|c|c|c|c|c|c|c|c|}
\hline $\mathrm{pH}$ & $\mathrm{MO}$ & $P$ & $\mathrm{~K}$ & $\mathrm{Ca}$ & $\mathrm{Mg}$ & $\mathrm{H}+\mathrm{Al}$ & $\overline{A l}$ & $\mathrm{~T}$ & $\mathrm{t}$ & $\bar{m}$ & $\mathrm{~V}$ \\
\hline$\overline{\text { água }}$ & $\mathrm{g} \mathrm{kg}^{-1}$ & $\mathrm{mg} \mathrm{dm}^{-3}$ & $\overline{-\ldots-\cdots}$ & - & $\mathrm{cmol}_{\mathrm{c}}$ & $\mathrm{dm}^{-3}-$ & & & --- & $---\%$ & -- \\
\hline 4,9 & 29,8 & 22 & 0,25 & 1,99 & 1,29 & 8,2 & 1,77 & 11,76 & 5,3 & 35 & 30 \\
\hline
\end{tabular}


Desde 2011 a área é conduzida para avaliar sistemas agropastoris (integração Lavoura Pecuária) e agrossilvipastoris (integração Lavoura Pecuária e Floresta) na região.

Os sistemas ILPF avaliados possuem, nos entre renques, dois espaçamentos, de 18 metros e 42 metros onde planta-se soja na safra e geralmente milho consorciado com capim na entressafra. Os renques são compostos por dois clones de eucalipto (VM01 e GG100) e possuem quatro linhas de plantio, espaçadas entre si em 3,5 m e com espaçamento entre plantas de 3m (Figura 2).

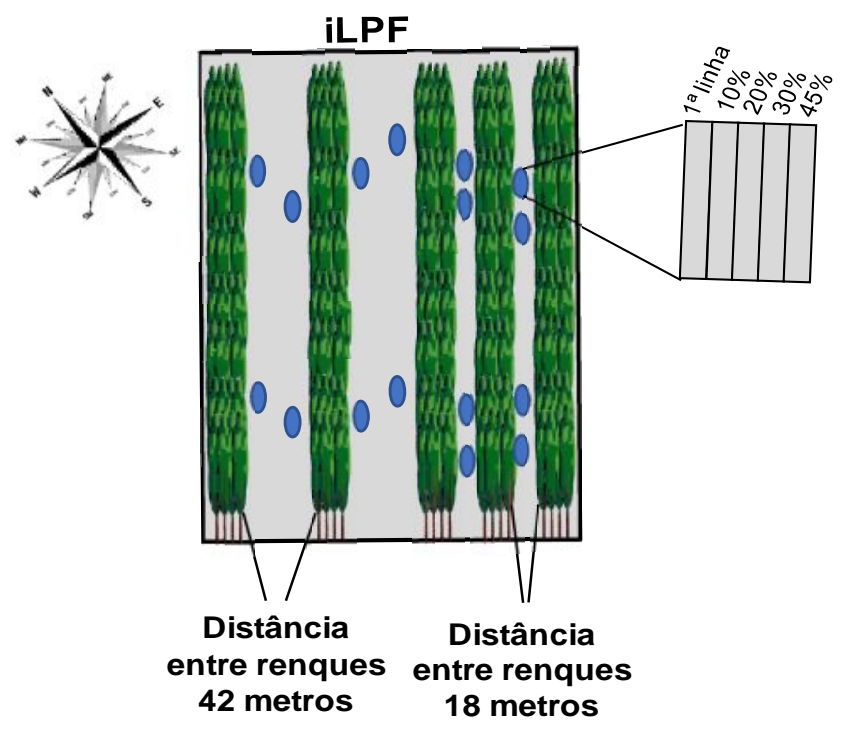

FIGURA 2. Área experimental com diferentes modelos de integração lavourapecuária-floresta (ILPF), no campo experimental da Embrapa, Porto Velho, Rondônia,. Fonte: Autores.

As amostragens foram realizadas em pontos distanciados, a partir do componente arbóreo, em 1\% (1 a linha), 10, 20, 30 e 45\% das distâncias dos espaçamentos dos entre renques de eucalipto (18 e $42 \mathrm{~m})$. As avaliações foram realizadas coletando-se amostras em 4 locais equidistantes ao longo do espaço entre os renques (direção NE-SO) a título de repetições (Figura 2). O delineamento experimental utilizado foi em blocos casualizados em esquema de parcela subsubdividida no espaço, compreendendo as parcelas os diferentes espaçamentos entre renques (18 e 42m), os clones as subparcelas e as distâncias a partir dos renques as sub-subparcelas.

Foram semeadas, de forma simultânea, a cultivar de sorgo IPA 70301011 consorciado com capim braquiária brizantha Xaraés em 15 de abril de 2017, fora do período recomendado de semeadura do sorgo para a região. O espaçamento de entrelinhas foi de $0,45 \mathrm{~m}$ e utilizou-se uma densidade de semeadura vislumbrando-se uma população inicial de 260.000 plantas por hectares. Aplicou-se uma adubação de semeadura de $300 \mathrm{~kg}$ do formulado 00-30-15 (NPK) e 10\% de Ca, ou seja, $90 \mathrm{~kg}$ de $\mathrm{P}_{2} \mathrm{O}_{5} \mathrm{ha}^{-1}, 45 \mathrm{~kg}$ de $\mathrm{K}_{2} \mathrm{O} \mathrm{ha}^{-1}$ e $30 \mathrm{~kg} \mathrm{Ca} \mathrm{ha}^{-1}$. Foram realizadas duas adubações de cobertura, totalizando $500 \mathrm{~kg}$ de $25-00-25$, ou seja, $125 \mathrm{~kg}$ de N ha-1 e $125 \mathrm{~kg}$ de $\mathrm{K}_{2} \mathrm{O} \mathrm{ha}^{-1}$. Os demais tratos culturais foram realizados conforme preconizado para a cultura. 
Foram avaliados os seguintes atributos agronômicos da cultura do sorgo: índice de panícula (número de panículas por planta), alturas de planta $(\mathrm{cm})$, massa de mil grãos $(\mathrm{g})$ e rendimento de grãos $\left(\mathrm{kg} \mathrm{ha}^{-1}\right)$, com umidade corrigida para $13 \%$. $\mathrm{Na}$ planta forrageira mensurou-se o rendimento de massa da matéria seca $\left(\mathrm{kg} \mathrm{ha}^{-1}\right)$.

Para análise dos dados, os mesmos foram submetidos à análise de variância com auxílio do software Sisvar. As médias, quando obtida significância pelo teste $F$, foram comparadas por meio do teste de Tukey, a $5 \%$ de probabilidade e regressões polinomiais para as distâncias a partir das árvores.

\section{RESULTADOS E DISCUSSÃO}

Verificou-se efeito dos tratamentos sob todas as variáveis avaliadas (Tabela 2). Para o rendimento de biomassa do capim consorciado, foi identificado um efeito de interação tripla para a variável. Por sua vez, a interação dupla entre os clones e as distâncias a partir do componente arbóreo, só não foram identificadas nessa variável e na massa de mil grãos na cultura do sorgo. A interação entre os tipos de renques e clones só afetou o diâmetro do colmo da cultura do sorgo, não influenciando as demais variáveis.

TABELA 2. Resumo da análise de variância para rendimento de grãos (RG), altura de planta (AP), índice de panícula (IP), massa de mil grãos (MMG) e massa da matéria seca do capim (MS), em função da distância entre o renque (18 e 42 m), clones de eucalipto (GG100 e VM01) e distância $(1,10,20,30$ e $45 \%)$ da linha de semeadura em relação aos renques Porto Velho, Rondônia, 2017.

\begin{tabular}{|c|c|c|c|c|c|c|}
\hline \multirow{2}{*}{ Fonte de Variação } & \multirow{2}{*}{ GL } & \multicolumn{5}{|c|}{ Quadrados médios } \\
\hline & & RG & $\mathbf{A P}$ & IP & MMG & MS \\
\hline Bloco & 3 & 1331771 & 611,9 & 0,03 & 12,2 & 217803,9 \\
\hline Renque (R) & 1 & 23872907,6 * & 1117 & 0,56 * & 85,9 & 5426,5 \\
\hline Resíduo (a) & 3 & 1216065 & 170,4 & 0,03 & 10,6 & 811097,1 \\
\hline Clones (C) & 1 & 4872845 & 4490,0 ** & 0,07 & 0,7 & 522887,2 \\
\hline $\mathrm{R} \times \mathrm{C}$ & 1 & 930181,3 & 1388,9 * & 0 & 2,7 & 155418,7 \\
\hline Resíduo (b) & 6 & 3298064 & 198,8 & 0,01 & 5,8 & 1056599,4 \\
\hline Distância (D) & 4 & $6737573,8^{* \star}$ & $2509,9 * *$ & $0,05^{* *}$ & $19,1^{* *}$ & 256678,3 \\
\hline$R \times D$ & 4 & $3174882,7^{* *}$ & 1006,4 ** & 0,02 & 0,8 & $1034113,5^{* *}$ \\
\hline$C \times D$ & 4 & 2892741,4 ** & $1517,1^{\star *}$ & $0,07^{* *}$ & 3,1 & 241247,3 \\
\hline$R \times C \times D$ & 4 & 496162,3 & 97,5 & 0,02 & 8,8 & 581250,5 * \\
\hline Resíduo (c) & 48 & 526844,1 & 183,3 & 0,01 & 3,4 & 219563 \\
\hline C.V.p (\%) & & 53,1 & 13,1 & 24,2 & 15,8 & 44,7 \\
\hline C.V. sp (\%) & & 87,4 & 14,1 & 11,3 & 11,7 & 51,1 \\
\hline C.V. ssp (\%) & & 35 & 13,5 & 15,3 & 9 & 23,3 \\
\hline
\end{tabular}

**, * significativo, pelo teste $\mathrm{F}$, a $1 \%$ e $5 \%$ de probabilidade, respectivamente.

Verificou-se a influência dos diferentes níveis e competição nos clones de eucalipto, expressos por diferentes densidades de árvores e distanciamento da sombra florestal sobre a cultura. O entendimento da dinâmica e comportamento do sorgo nesses sistemas é fundamental visando consolidar a cultura como uma planta alternativa para sistemas integrados complexos envolvendo componente florestal. A planta do sorgo é adaptada para condições de estresses edáficos climáticos como solos distróficos e álicos (SANTOS et al., 2018) e déficit hídrico moderado (PERAZZO et al., 2013), o que lhe garante uma posição de destaque em condições ENCICLOPÉDIA BIOSFERA, Centro Científico Conhecer - Goiânia, v.15 n.28; p.1405 2018 
de semeadura tardia nas áreas de cerrado, para recuperação de pastagens em solos de fertilidade baixa e média e em consórcio com plantas forrageiras.

Os atributos rendimento de grãos (RG), índice de panícula (IP) e massa de mil grãos (MMG) não apresentaram diferença para os diferentes clones (GG100 e VM01), dentro das duas distâncias entre renques (18 e 42m) (Tabela 3). A altura de planta foi influenciada $(p<0,05)$ pelas diferentes distâncias do componente florestal no espaçamento de entre renque de $18 \mathrm{~m}$.

TABELA 3. Médias de rendimento de grãos $(R G)$, altura de planta $(A P)$ e índice de panícula (IP), massa de mil grãos (MMG), da cultura do sorgo nos renques de 18 e 42 m, em função dos clones de eucalipto (GG100 e VM01), no município de Porto Velho, Rondônia, 2017.

\begin{tabular}{|c|c|c|c|c|c|}
\hline \multirow{2}{*}{ Renques } & \multicolumn{2}{|r|}{$\mathbf{R G}$} & \multirow{2}{*}{$\begin{array}{l}\text { AP } \\
(\mathrm{cm})\end{array}$} & \multirow{2}{*}{$\frac{\text { IP }}{\left(\text { panículas }^{-1} \text { planta }^{-1}\right)}$} & \multirow{2}{*}{$\begin{array}{c}\text { MMG } \\
(\mathrm{g})\end{array}$} \\
\hline & Clones & $\left(\mathrm{kg} \mathrm{ha}^{-1}\right)$ & & & \\
\hline \multirow{2}{*}{18} & GG100 & $2.977,59 \mathrm{a}$ & $107,93 \mathrm{~A}$ & $0,87 \mathrm{a}$ & $19,28 b$ \\
\hline & VM01 & $2.268,33$ & $84,61 \mathrm{bB}$ & $0,83 \mathrm{a}$ & 19,83 \\
\hline \multicolumn{2}{|c|}{ Média renque de $18 \mathrm{~m}$} & $2.622,96 \mathrm{~A}$ & 96,27 & $0,85 \mathrm{~A}$ & 19,55 \\
\hline \multirow{2}{*}{42} & GG100 & $1.669,39 \mathrm{~b}$ & 107,07 & $0,72 \mathrm{bA}$ & $21,72 \mathrm{a}$ \\
\hline & VM01 & $1.391,45$ & $100,42 \mathrm{a}$ & $0,65 \mathrm{bB}$ & 21,53 \\
\hline \multicolumn{2}{|c|}{ Média renque de $42 m$} & $1.530,42 \mathrm{~B}$ & 103,75 & $0,68 \mathrm{~B}$ & 21,62 \\
\hline
\end{tabular}

Médias seguidas por letras, maiúscula dentro dos renques e minúscula entre os renques, não diferem entre si Scott Knott $(p<0,05)$.

O rendimento de grãos do sorgo no entre renque de 18 metros foi $71 \%$ $\left(1.092,54 \mathrm{~kg} \mathrm{ha}^{-1}\right)$ superior quando comparado aos dados obtidos no entre renque de 42 metros $\left(1.530,42 \mathrm{~kg} \mathrm{ha}^{-1}\right)$. Observa-se que no período após a semeadura do sorgo com o capim houve um acumulado de precipitação de apenas $157 \mathrm{~mm}$ (Figura 1) sobre o experimento, demonstrando um alto nível de estresse hídrico, com precipitação pluviométrica insuficiente para que a cultura completasse o ciclo natural. A superioridade na produção de grãos na cultura quando posicionada entre plantas arbóreas pode ter ocasionado mudanças na dinâmica da água com diminuição na evaporação de água do solo e diminuição da transpiração vegetal. Dessa forma, renques mais adensados, como os do experimento, com 18 metro entre as aleias, podem modificar o microclima promovendo maior resiliência das lavouras às condições de estresse hídrico durante a seca.

Observou-se efeito das distâncias das plantas a partir do componente florestal para o rendimento de grãos, altura de plantas e índice de panícula, com comportamentos diferenciados devido ao efeito do clone de eucalipto presente (figura 3). Para o clone VM01, verificou-se um incremento linear do rendimento de grãos quando houve recuo das plantas em relação às árvores, mensurando-se as maiores produtividades de grãos no meio do renque, local que apresenta menor influência das árvores. Por sua vez, o clone GG100 influenciou menos o rendimento de grãos quando as plantas se encontravam próximas desse clone. Conduto, a produtividade de grãos na posição mediano do espaço entre renque, foi próximo do observado no clone VM01. Sob influência dos clones VM01 e GG100 verificou-se rendimentos médios de grãos de $1.829,89$ e $2.323,49 \mathrm{~kg} \mathrm{ha}^{-1}$, respectivamente. A diferença na produtividade observada entre clones foi de 493,6 $\mathrm{kg} \mathrm{ha}^{-1}$, o que ENCICLOPÉDIA BIOSFERA, Centro Científico Conhecer - Goiânia, v.15 n.28; p.1406 2018 
representa um decréscimo de $27 \%$ quando o sorgo é cultivado no entre renques do clone VM01. Isto pode ocorrer devido ao fato do clone GG100 ter apresentado maior mortalidade de plantas próximo a área das parcelas.
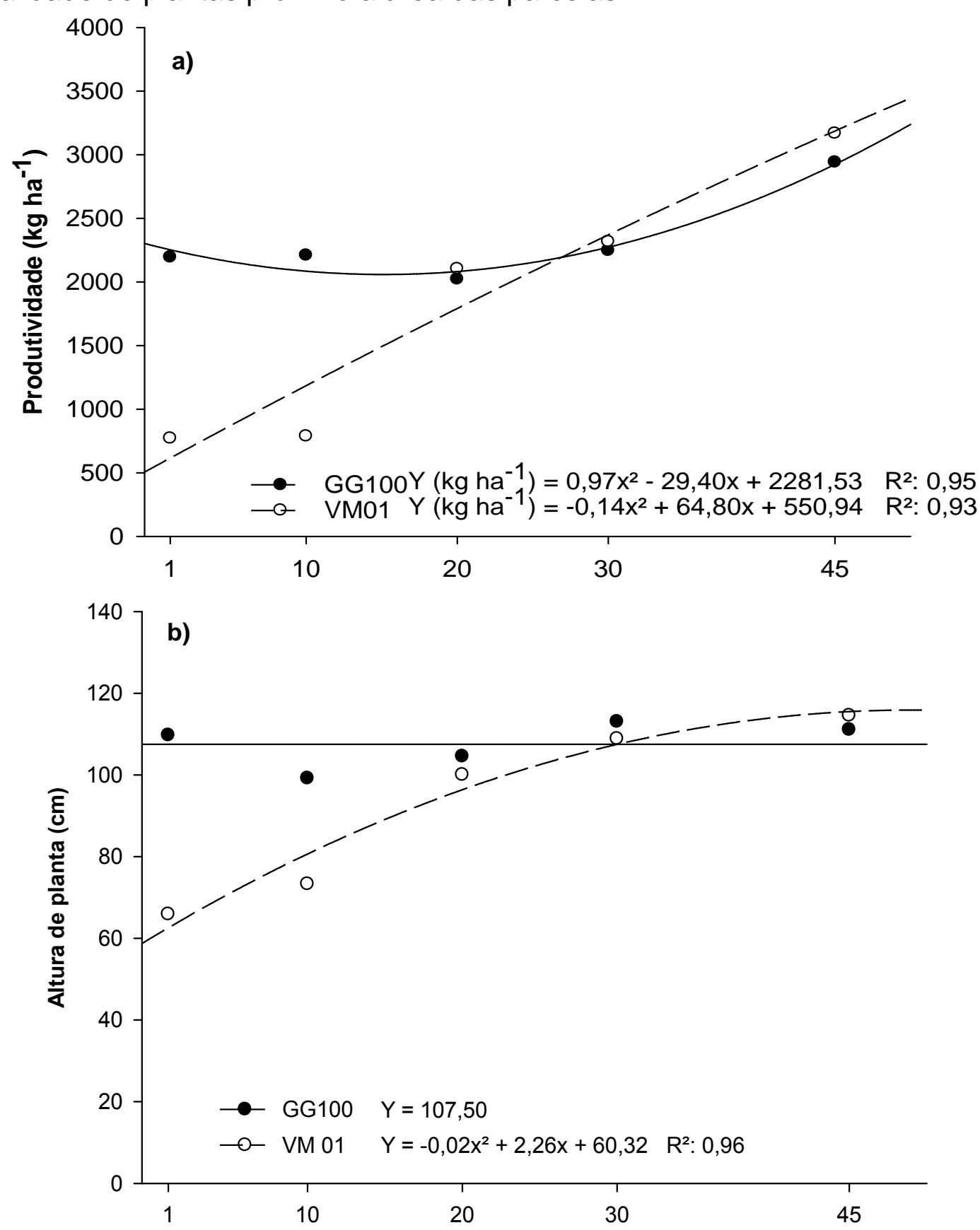


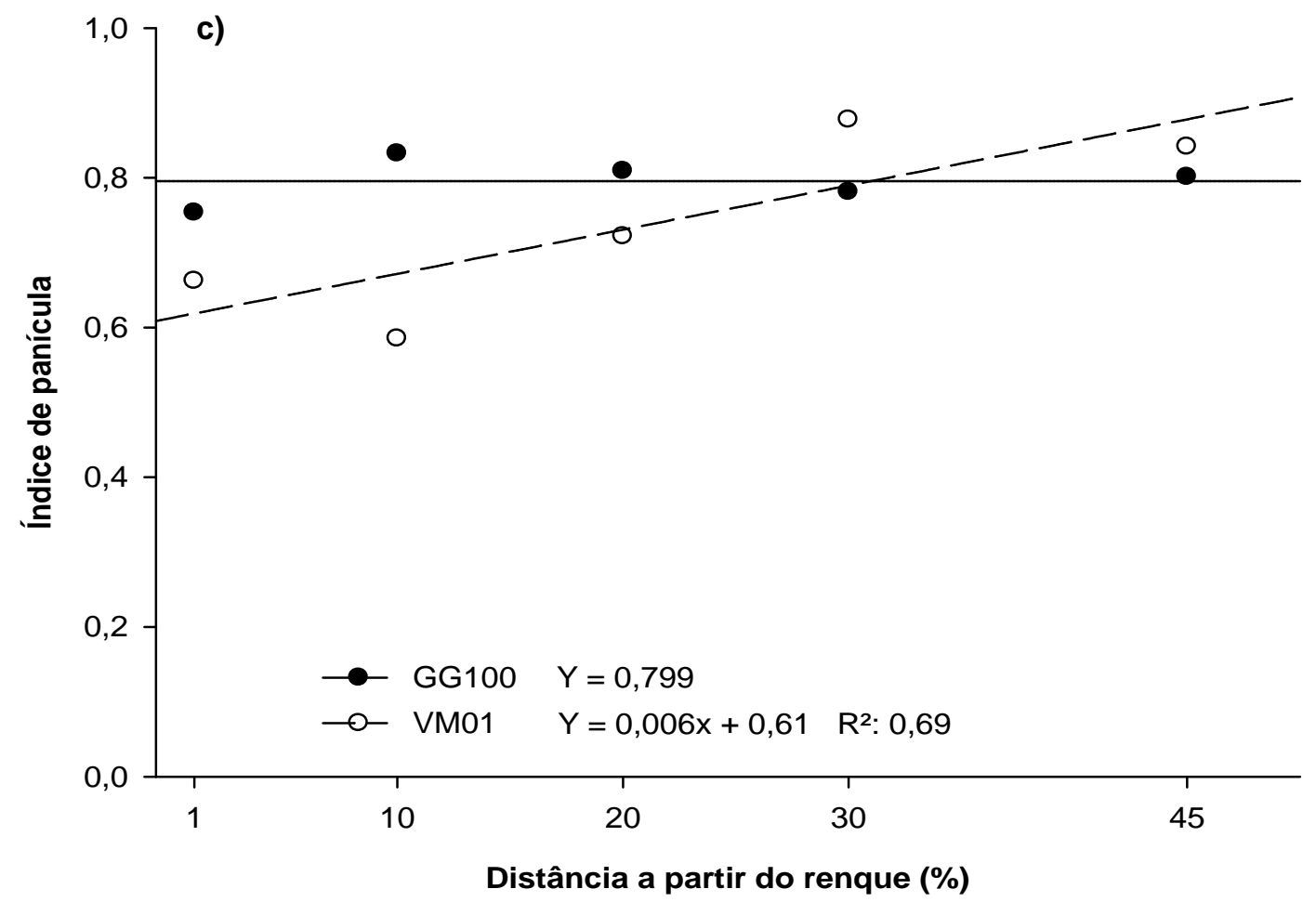

FIGURA 3. Efeito do clone (GG100 e VM01) e distância do renque $(0,1,10,20,30$ e $45 \%$ ) sobre o (a) rendimento de grãos, (b) altura de planta e (c) índice de panícula na cultura do sorgo, Porto Velho, Rondônia, 2017. Fonte: Autores.

As plantas de sorgo cultivadas entre o clone GG100 apresentaram uma variação de rendimento de grãos de $33 \%$ entre a primeira linha de semeadura $\left(2.195,8 \mathrm{~kg} \mathrm{ha}^{-1}\right)$ para a distância de $45 \%\left(2.941,8 \mathrm{~kg} \mathrm{ha}^{-1}\right)$ a partir do renque. Já para o clone VM01, o menor rendimento de grãos $\left(772 \mathrm{~kg} \mathrm{ha}^{-1}\right)$ foi observado na proximidade do renque e o maior rendimento $\left(3.168,5 \mathrm{~kg} \mathrm{ha}^{-1}\right)$ foi obtido no ponto mais distanciado do componente florestal representando um acréscimo superior à

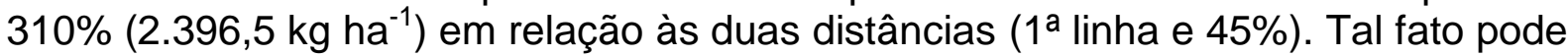
derivar da maior formação de copa, proporcionando assim, maior sombreamento para o sorgo nesse clone nas plantas mais próximas das árvores.

A produtividade média do sorgo nos dois clones ficou abaixo da média nacional na safra 2016/17 (2.967 $\left.\mathrm{kg} \mathrm{ha}^{-1}\right)$. Contudo, o desempenho médio da lavoura cultivada entre renques constituído pelo clone GG100, na média dos dois renques $\left(2.323,5 \mathrm{~kg} \mathrm{ha}^{-1}\right)$, foi satisfatório quando comparado com a produtividade média do Mato Grosso, que foi de $2.470 \mathrm{~kg} \mathrm{ha}^{-1}$ na safra 2017, representando apenas 2,4 sacas $\mathrm{ha}^{-1}(146,5 \mathrm{~kg})$ a menos que a média estadual daquele estado (CONAB, 2018).

A variável altura de planta foi influenciada pelo componente florestal. As plantas em crescimento entre o clone GG100 apresentaram altura média de 107,5 $\mathrm{cm}$, o que representa $16,2 \%(15 \mathrm{~cm})$ a mais quando comparada à média do clone VM01 $(92,5 \mathrm{~cm})$. As plantas cultivadas entre os clones VM01 apresentaram variação de $73,8 \%(15 \mathrm{~cm})$, sendo a menor altura $(65,9 \mathrm{~cm})$ obtida na primeira linha de semeadura, e a maior $(114,5 \mathrm{~cm})$ na distância de $45 \%$ a partir do renque. Já para o clone GG100, essa variação foi de apenas $1,2 \%(1,3 \mathrm{~cm})$ entre as distâncias. A redução da altura das plantas entre o clone VM01, nas duas primeiras distâncias chegaram a quase $50 \%(34,8 \mathrm{~cm})$, quando comparada ao GG100. Esse fato pode ENCICLOPÉDIA BIOSFERA, Centro Científico Conhecer - Goiânia, v.15 n.28; p.1408 
ser em decorrência da menor oferta de radiação fotossinteticamente ativa proporcionada pelos diferentes clones, uma vez que a medida que se afasta do eucalipto, a diferença de altura do sorgo entre os clones diminui até a distância de $30 \%$, chegando a ser $3,5 \mathrm{~cm}$ maior nas distâncias de $45 \%$.

O clone de eucalipto GG 100 não influenciou nos resultados para o atributo índice de panícula (IP) cuja média foi de 0,8 panículas por planta. Já o clone VM01 apresentou crescimento linear para o índice de panícula, semeado entre o clone VM0, variando em $27 \%$, em relação a distância do eucalipto. O melhor índice de panícula no clone VM01 foi obtido na distância de 30\% (0,88 panículas por planta) em relação ao renque. Esses atributos agronômicos são importantes, uma vez que segundo Nyadanu e Dikera (2014), o número, diâmetro e o comprimento de panícula são características agronômicas diretamente relacionadas ao rendimento da cultura.

Os melhores resultados obtidos para a maioria dos atributos agronômicos do sorgo, sob a influência do clone GG100, pode ser atribuído ao maior número de plantas mortas próximo as parcelas avaliadas, proporcionando maior interceptação de radiação pela cultura (ALBUQUERQUE, et. al., 2016). A quantidade de radiação que atinge a cultura pode influenciar as características agronômicas da cultura (MARINA et al., 2015).

Ao avaliar o comportamento da cultura devido ao distanciamento das árvores, separadamente para cada renque, verifica-se que para o renque de 18 metros houve um comportamento crescente de rendimentos de grãos, enquanto que para o renque de 42 metros, o rendimento de grãos, que foi máximo próximo dos 15 metros e decrescente a partir dessa distância das árvores (Figura 4).

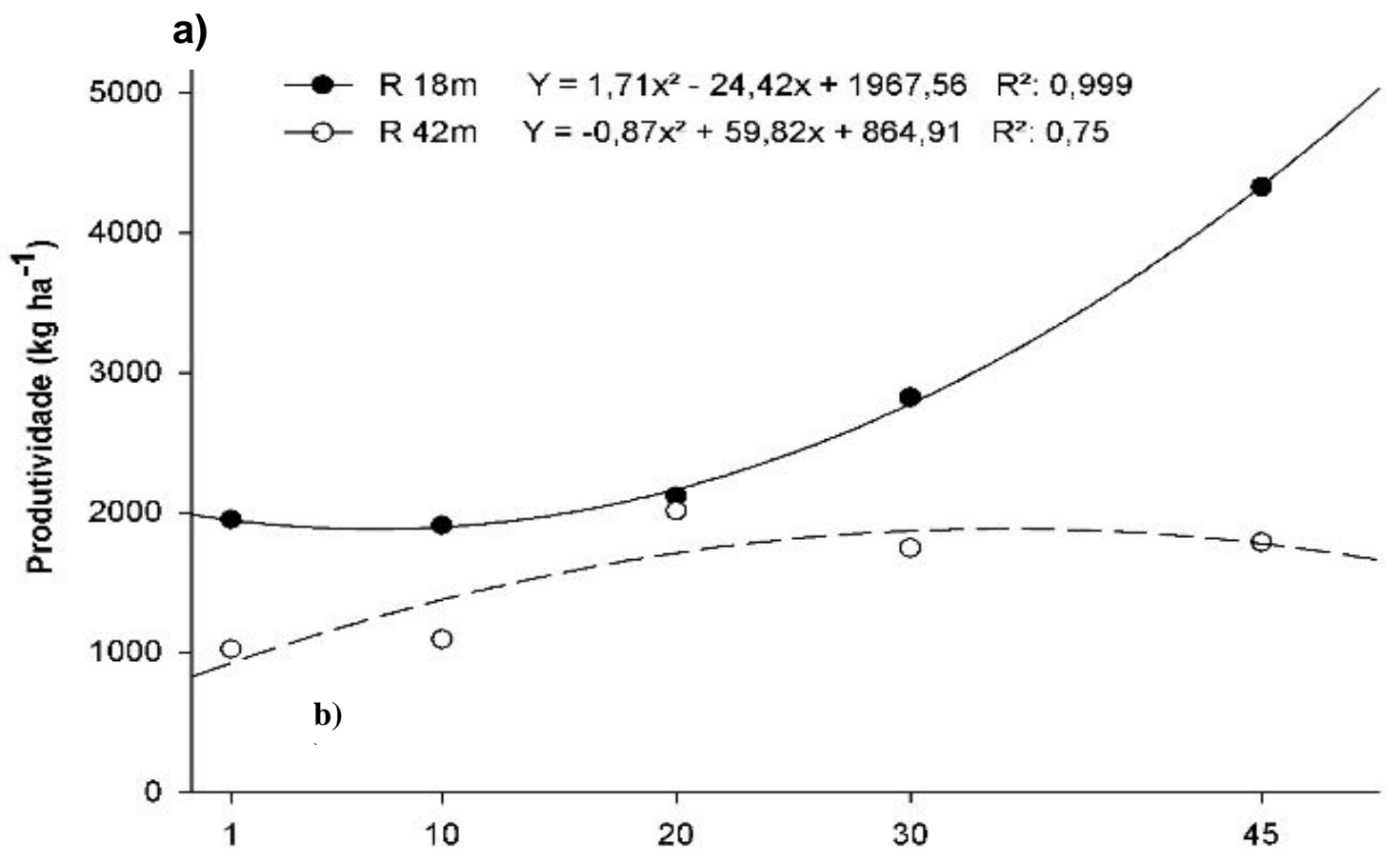



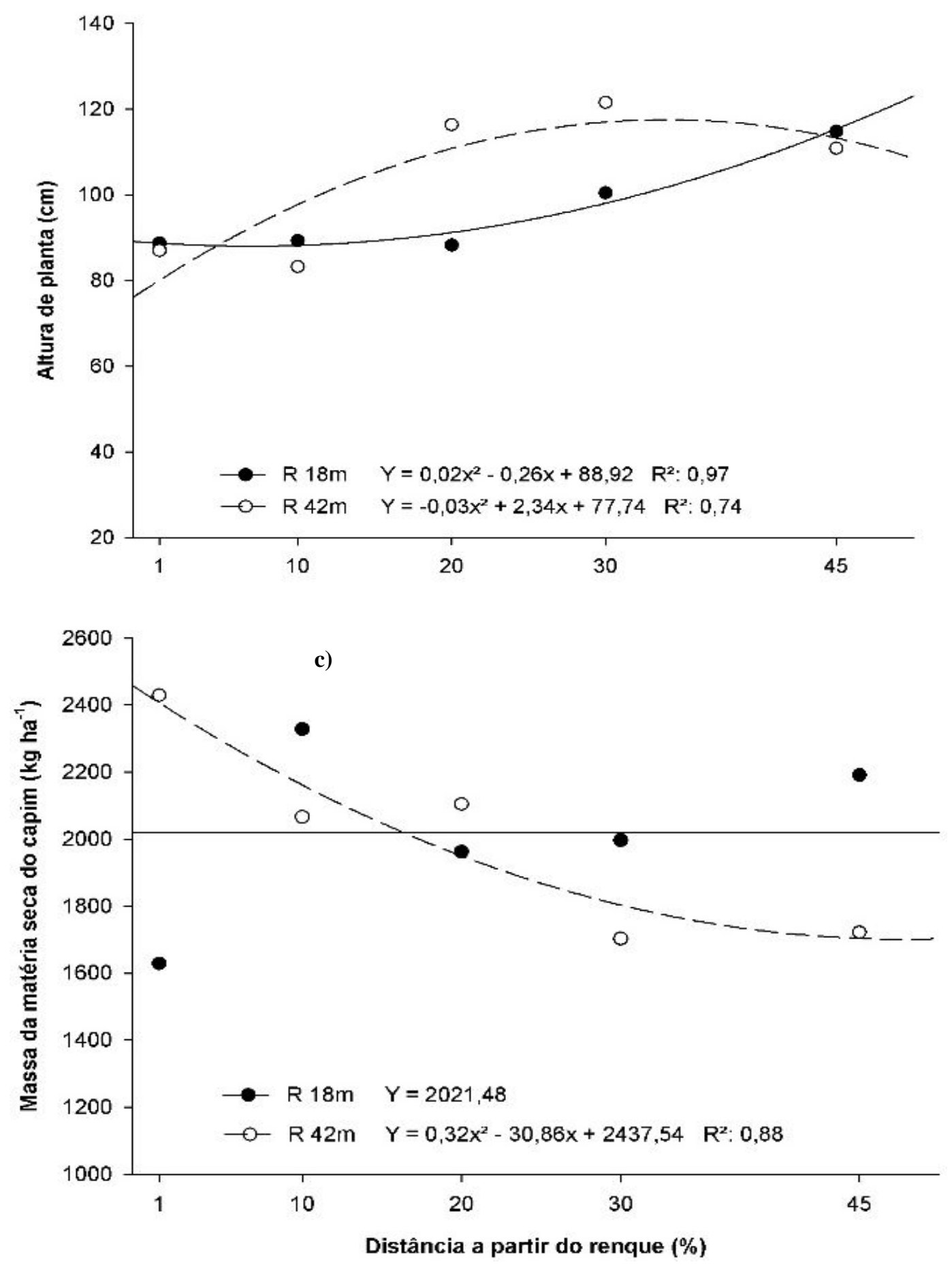

FIGURA 4 - Efeito de renque (18 e $42 \mathrm{~m}$ ) e distância dentro do renque $(0,1,10,20$, 30 e $45 \%$ ) sobre o rendimento de grãos (a), altura de planta (b) e massa da matéria seca do capim (c) na cultura do sorgo, Porto Velho, Rondônia, 2017. Fonte: Autores.

A partir dessa distância, houveram modificações biofísicas do ambiente, influenciado pelas árvores, que promoveram maior demanda de água e ou evapotranspiração do sistema. A cultura do sorgo é capaz de manter-se em estados latentes de crescimento e desenvolvimento como resposta às condições de estresse ambiental, em mecanismos de tolerância à seca similares à dormência fisiológica (BENECH-ARNOLD et al., 2018). Dessa forma, verificou-se que para o renque de 42 
metros houve um maior crescimento das plantas, derivado de sua atividade anabólica, o que gera maior demanda de energia e, portanto, água. Nesse sentido, em condições de baixa disponibilidade hídrica, o crescimento vegetal em altura pode representar um dreno energético que irá refletir negativamente sobre o rendimento de grãos das plantas.

Similarmente, observou-se maior crescimento e acúmulo de biomassa do capim no renque de 42 metros (figura 4). Em um consórcio de plantas, quando um dos componentes, no caso o sorgo, apresenta um crescimento maior, mais proeminente, a planta consorte, no caso o capim, irá sofrer maior nível de competição e inibição competitiva crescendo menos e acumulando menos biomassa. Não se observou efeito do distanciamento a partir das árvores sobre o rendimento de massa da matéria seca do capim no renque de 18 metros

Ao estudar o desdobramento da interação tripla dos fatores sobre 0 rendimento de biomassa da matéria seca do capim, verificou-se que não houve influência das distâncias a partir dos renques de eucalipto, em sistema ILPF para o clone GG100. Esse resultado pode ser devido ao fato que o clone GG 100 apresentou maior desfolhamento e mortalidade de planta quando comparado ao VM01, uma vez que o mesmo se mostrou susceptível à mancha-dephaeophleospora quando em sistema integrado nesses modelos na região norte de Rondônia (VIEIRA JUNIOR et al., 2014).

A morfologia da copa (tamanho e quantidade de galhos), influencia na interceptação luminosa que chega ao solo (PRETZSCH, 2014). Dessa forma, o clone GG100 permite maior entrada de radiação fotossintética, elemento fundamental para a realização dos processos metabólicos de fixação de carbono e acúmulo de biomassa nas plantas.

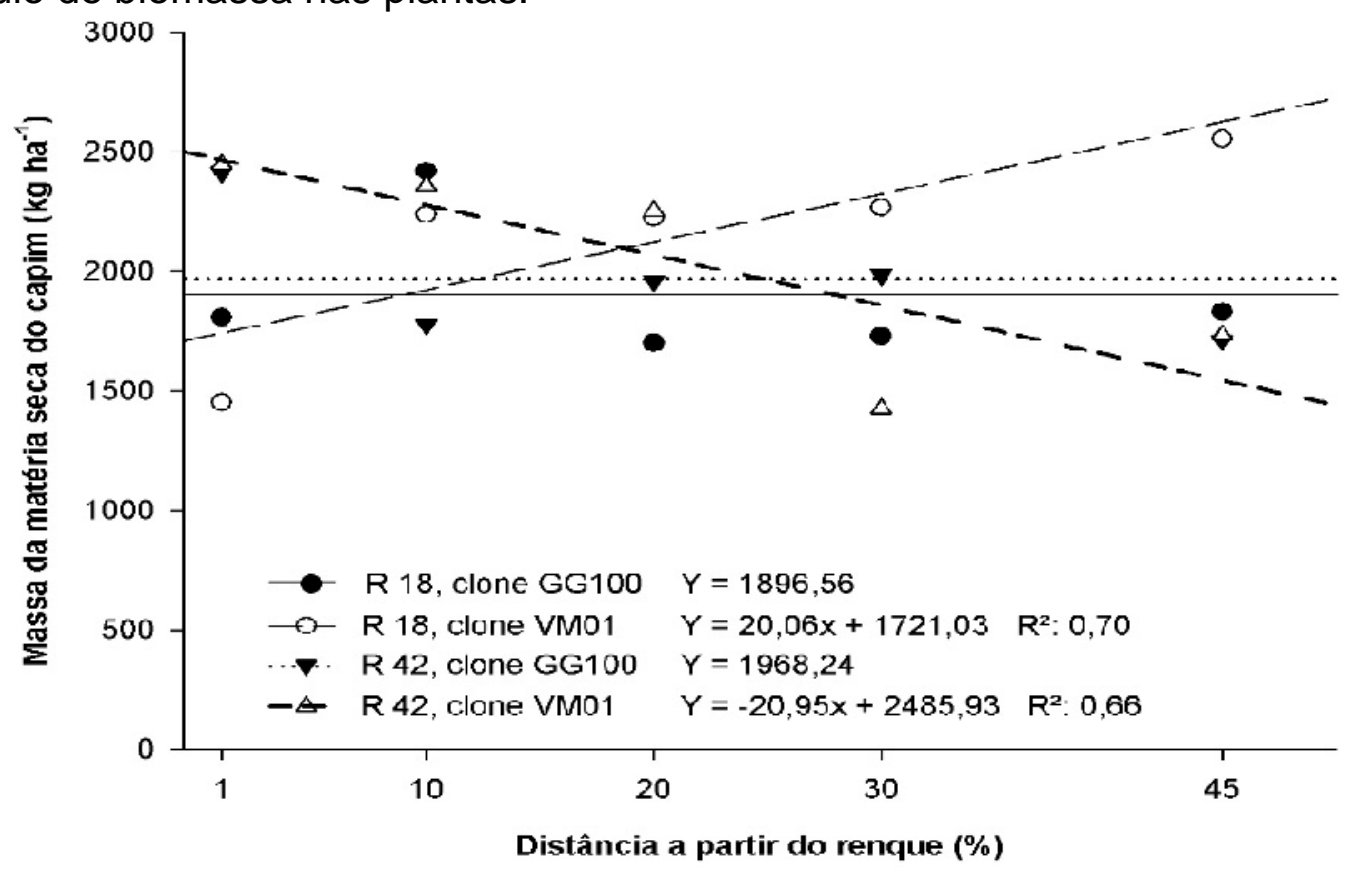

FIGURA 5 - Efeito do espaçamento entre renques (18 e 42 m), clone (GG100 e VM01) e distância no entre renque $(0,1,10,20,30$ e 45\%) sobre a massa da matéria seca do capim (MS) na cultura do sorgo, Porto Velho, Rondônia, 2017. Fonte: Autores.

Verificou-se um incremento linear no rendimento de biomassa do capim quando o mesmo encontra-se no entre renque de 18 metros. Tal fato pode decorrer ENCICLOPÉDIA BIOSFERA, Centro Científico Conhecer - Goiânia, v.15 n.28; p.1411 
do maior acúmulo de nutrientes e água derivado da maior proximidade das árvores, que geram maior ciclagem de nutrientes pelas liteiras.

\section{CONCLUSÕES}

A cultura do sorgo, enquanto cultura sucessora da soja em semeaduras tardias no fechamento da safrinha, representa uma alternativa viável para compor sistemas de produção integrados consolidados.

O melhor desempenho da cultura do sorgo ocorreu no sistema mais adensado, possivelmente devido às mudanças de microclimas que promoveram menor evapotranspiração e aumento da disponibilidade de água no solo para as plantas.

O clone de eucalipto GG100 promove menor efeito de competição sobre a cultura do sorgo e capim consorciados que o clone de eucalipto VM01, em sistemas de integração lavoura pecuária e floresta com árvores com 5 anos de idade.

\section{AGRADECIMENTOS}

Ao CNPq pelo apoio financeiro (processo 459130/2014-5). À CAPES/FAPERO pela concessão da bolsa de estudo.

\section{REFERÊNCIAS}

ALBUQUERQUE, C. J. B.; SOARES, W. S.; LANA, R. M. Q.; SANTOS, G. C. DOS. Agronomic characteristics of sorghum in an agroforestry system with Eucalyptus in the semiarid region of Minas Gerais. African Journal of Agricultural Research, v. 11, n. 33, p. 3104-3110, 2016. Dispnível em: <https://doi.org/10.5897/AJAR2016.11205>. doi: 10.5897/AJAR2016. 11205

ALVARES, C. A.; STAPE, J. L.; SENTELHAS, P. C.; DE MORAES GONÇALVES, J. L.; SPAROVEK, G. Köppen's climate classification map for Brazil. Meteorologische Zeitschrift, v. 22, n. 6, p. 711-728, 2013. Disponível em: <https://dx.doi.org/10.1127/0941-2948/2013/0507>. doi:10.1127/09412948/2013/0507

BENECH-ARNOLD, R. L.; RODRÍGUEZ, M. V. "Pre-Harvest Sprouting and Grain Dormancy in Sorghum Bicolor: What Have We Learned?" Frontiers in Plant Science v. 9: 811, 2018. <https://doi.org/10.3389/fpls.2018.00811>. doi: 10.3389/fpls.2018.00811

CANIATO, F. F.; HAMBLIN, M. T.; GUIMARAES, C. T.; et al. Association Mapping Provides Insights into the Origin and the Fine Structure of the Sorghum Aluminum Tolerance Locus, AltSB. PLOS ONE, v. 9, n. 1, p. e87438, 2014. Disponível em: <https://doi.org/10.1371/journal.pone.0087438>.

CLEMENTE, M. V.; ZANDONADI, S. H. S.; LANA, R. M. Q.; FRANCO, F. O.; ALBUQUERQUE, C. J. Agricultural characteristics and evaluation locations of sorghum plots with different eucalyptus arrangements. African Journal of Agricultural Research, v. 10, n. 32, p. 3093-3100, 2015. Disponível em: <https://doi.org/10.5897/ajar2015.9957>. doi 10.5897/AJAR2015.9957

COMPANHIA NACIONAL DE ABASTECIMENTO - CONAB. Acompanhamento da safra brasileira de grãos, v. 11 Safra 2017/18 - Décimo primeiro levantamento, 
Brasília, p. 1-148, agosto 2018. Disponível em: < https://www.conab.gov.br/infoagro/safras/graos >. Acesso em: 21/08/2018.

EMPRESA BRASILEIRA DE PESQUISA AGROPECUÁRIA - EMBRAPA. Sistema brasileiro de classificação de solos. 3a edição revista e ampliada ed. Brasília, DF: Embrapa, 2013.

INSTITUTO NACIONAL DE METEOROLOGIA - INMET. Estações e dados: Estações automáticas. Brasília, DF, 2017. Disponível em: < http://www.inmet.gov.br/portal/index.php?r=estacoes/estacoesAutomaticas $>$. Acesso em: 01 jul. 2017.

NYADANU, D.; DIKERA, E. Exploring variation, relationships and heritability of traits among selected accessions of sorghum (Sorghum bicolor L. Moench) in the Upper East region of Ghana. Journal of Plant Breeding and Genetics, v. 2, n. 3, p. 101107, 2014. ISSN 2305-297X. Disponível em: <http://www.escijournals.net/index.php/JPBG/article/view/487>

PERAZZO, A. F.; SANTOS, E. M.; PINHO, R. M. A.; CAMPOS, F. S.; RAMOS, J.P. de F., et al. Características agronômicas e eficiência do uso da chuva em cultivares de sorgo no semiárido. Ciência Rural, Santa Maria, v. 43, n. 10, p. 1771-1776, out, 2013. Disponível em: <http://dx.doi.org/10.1590/S0103-84782013001000007>.

PRETZSCH, H. Canopy space filling and tree crown morphology in mixed-species stands compared with monocultures. Forest Ecology and Management, v. 327, p. 251-264, 2014. DOI: 10.1016/j.foreco.2014.04.027. Disponível em: < https://doi.org/10.1016/j.foreco.2014.04.027>.

SANTOS, C. V. DOS; SILVA, N. S.; MAGALHÃES, J. V.; SCHAFFERT, R. E.; MENEZES, C. B. DE. Performance of grain sorghum hybrids in soils with low and high aluminum saturation. Pesquisa Agropecuária Tropical, v. 48, n. 1, p. 12-18, 2018.Disponível em: <http://dx.doi.org/10.1590/1983-40632018v4848851>. doi: $0.1590 / 1983-4063 / 2018 /$

SCHLINDWEIN, J. A.; MARCOLAN, A. L.; FIORELI-PERIRA, E. C.; PEQUENO, P. L. de L.; MILITÃO, J. S. T. L. Solos de Rondônia: Usos e Perspectivas. Revista Brasileira de Ciências da Amazônia, v. 1, n. 1, p. 2013-231. 2012. ISSN: 23175729. em:

http://www.periodicos.unir.br/index.php/rolimdemoura/article/view/612/660>

SILVA, A. G. DA; MORAES, L. E. DE; HORVATHY NETO, A.; TEIXEIRA, I. R.; SIMON, G. A. Consórcio sorgo e braquiária na entrelinha para produção de grãos, forragem e palhada na entressafra. Revista Ceres, v. 61, n. 5, p. 697-705, 2014. Disponível em: <http://dx.doi.org/10.1590/0034-737X201461050013>.

UNITED STATES DEPARTAMENT OF AGRICULTURE - USDA. Foreign Agricultural Service. Disponível em: <https://www.fas.usda.gov/>. Acesso em: 21 agosto. 2018. 